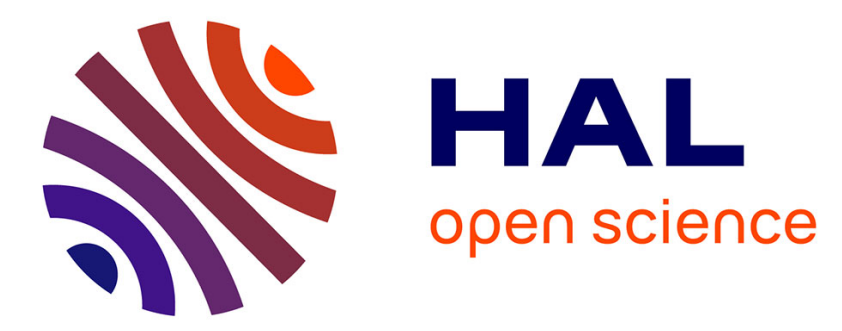

\title{
Hypoeutectic Aluminum-Silicon Alloy Development for GMAW-Based 3-D Printing Using Wedge Castings
}

\author{
Amberlee Haselhuhn, Paul G Sanders, Joshua Pearce
}

\section{To cite this version:}

Amberlee Haselhuhn, Paul G Sanders, Joshua Pearce. Hypoeutectic Aluminum-Silicon Alloy Development for GMAW-Based 3-D Printing Using Wedge Castings. International Journal of Metalcasting, 2017, 11 (4), pp.843-856. 10.1007/s40962-017-0133-z . hal-02113468

\section{HAL Id: hal-02113468 \\ https://hal.science/hal-02113468}

Submitted on 28 Apr 2019

HAL is a multi-disciplinary open access archive for the deposit and dissemination of scientific research documents, whether they are published or not. The documents may come from teaching and research institutions in France or abroad, or from public or private research centers.
L'archive ouverte pluridisciplinaire HAL, est destinée au dépôt et à la diffusion de documents scientifiques de niveau recherche, publiés ou non, émanant des établissements d'enseignement et de recherche français ou étrangers, des laboratoires publics ou privés. 


\title{
Hypoeutectic Aluminum-Silicon Alloy Development for GMAW-Based 3-D Printing Using Wedge Castings
}

\author{
Amberlee S. Haselhuhn ${ }^{1}$, Paul G. Sanders ${ }^{1}$, Joshua M. Pearce ${ }^{1,2}$ \\ ${ }^{1}$ Department of Materials Science \& Engineering, Michigan Technological University, \\ Houghton, MI, 49931, USA \\ 2 Department of Electrical \& Computer Engineering, Michigan Technological University, \\ Houghton, MI, 49931, USA
}

Authors’email addresses: aslifer@mtu.edu, sanders@mtu.edu, pearce@mtu.edu

Keywords: 3-D printing; additive manufacturing; aluminum; alloy development; metal casting; casting

\begin{abstract}
Alloy development can simplify low-cost gas metal arc weld (GMAW)-based 3-D printing by making it easier to print quality parts with minimal metallurgical or welding experience. Previous work found good properties in aluminum alloys, particularly in the aluminum-silicon 4943 (Al-5.5\%Si-0.4\%Mg) and 4047 (Al-11.6\%Si) alloys. These alloys were easy to print, but could benefit from alloying to increase ductility and to minimize or redistribute porosity. The purpose of this study was to modify 4943 and 4047 alloys and rapidly screen their performance for use as feedstock for improved 3-D printability. The 4047 and 4943-based alloys were modified with additions of magnesium, strontium, titanium boride, and combinations thereof. Wedge-shaped castings were used to efficiently screen alloying additions over the same ranges of solidification rates as those observed in GMAW-based 3-D printing. The alloying additions were most effective at modifying the high-silicon 4047 alloy whereas no change in microstructure was observed in the low-silicon 4943 alloy. Strontium was an effective modifier of the high-silicon alloy. Titanium boride was not observed to have a grain refining effect on aluminum dendrites on its own, although the combination of strontium and titanium boride produced the most refined eutectic structure in the high-silicon alloy. Future work should evaluate the singular effects of strontium, titanium boride, and the combination of strontium and titanium boride additions in weld-based 3-D printing.
\end{abstract}




\section{Introduction}

The process of additive manufacturing with metals currently begins with powder or filament. Energy is applied (in the form of an electron beam or laser) and a part is built layer by layer [1]. It is typically utilized in specialized industries such as for aerospace applications, medical implants, and surgical models [2]. Since less waste is produced by additive manufacturing compared to traditional manufacturing methods, the carbon footprint of manufacturing is reduced when additive processes are utilized [3]. For instance, the buy to fly ratio, commonly used by aerospace companies to represent the ratio between raw material weight and final part weight, is much smaller in additive manufacturing [4]. In subtractive manufacturing this number can be as large as 15-20 whereas in additive manufacturing this number is closer to 1 .

Additive manufacturing was first demonstrated with laser curing of photopolymers on a layer-by-layer basis in the 1960’s [2,5]. Yet it was not until the mid-2000's that metal 3-D printers became commercially available [6]. These metal printers utilized electron beams or lasers to selectively sinter or melt thin layers of metal powder according to instructions provided by a computer model in print resolutions on the micrometer scale. Common metal powders include stainless steels, Ti-6Al-4V, and nickel-based super alloys. Some electron beam or laser printers utilize wire feedstock to eliminate issues related to metal powder feeding and distribution [7]. An alternate method to 3-D print metal powders involves selectively printing a layer of liquid adhesive onto a thin layer of metal powder and subsequently sintered to burn off the adhesive and to sinter the metal particles [8]. Some of these metal powder printing techniques can be prohibitively expensive with equipment priced between $\$ 500,000-1.5$ million [9].

A more affordable metal 3-D printing technique utilizes gas metal arc welding (GMAW) technology and can be more than 500 times less expensive than traditional 3-D printing methods [10]. This technique is operated with a combination of open source electronics $[11,12]$ and open source software [13]. Not only is the equipment more economical than laser and powder methods, but the consumable weld wire is much more affordable, on the order of $\$ 4.50 /$ pound for 0.062" diameter stainless 316 wire versus $\$ 10$ per pound for an equivalent powder [14]. The low-cost GMAW-based printer can also produce parts in a matter of minutes or hours that would typically require days or weeks for laser or electron beam and powder printing methods. The concept of weld based printing, however, is not new as the first methods that can be described as weld-based 3-D printing were patented in 1972 to continuously weld circular vessels [15] and later in 1976 to produce large metal shafts and structural vessels [16]. GMAW-based 3-D printing is also known as wire and arc additive manufacturing (WAAM) [17]. This method of printing is closely related to single-layer multi-pass welding [18].

Recent studies with the low-cost GMAW-based printer developed substrate release mechanisms $[19,20]$ that enable the printers to operate as standalone units without expensive and time intensive cutting methods or other techniques to remove parts from the substrates. Previous work with the low-cost GMAW-based 3-D printer has shown that aluminum-silicon weld alloys may benefit most from alloy modification [21]. Alloys such as 4047 (Al-11.6\%Si) and 4943 (Al$5.5 \% \mathrm{Si}-0.4 \% \mathrm{Mg}$ ) were easy to weld and exhibited good mechanical properties [21]. The 
ductility and strengths of these alloys maybe further improved by a redistribution of porosity, refinement of the eutectic silicon morphology, and grain refinement.

\subsection{Eutectic Modification Strategies in Hypoeutectic Al-Si Alloys}

The eutectic structure of hypoeutectic aluminum-silicon alloys is commonly modified from a coarse, sharp, plate-like structure to a fine, fibrous structure with rounded edges to improve mechanical properties such as ductility and to redistribute porosity [22]. A method of modifying the eutectic structure in aluminum-silicon alloys using alkaline fluorides was first patented by Pacz [23]. Since then researchers studied the mechanisms attributed to sodium's ability modify the eutectic structure of aluminum-silicon alloys [24,25,26,27]. While effective, sodium was observed to fade rapidly in cast alloys and was difficult to control [28,29]. Although typically applied to cast aluminum-silicon alloys, Cross \& Olson applied similar practices to modify the eutectic structure of aluminum-silicon weld alloys [25]. Cross \& Olson evaluated whether additions of sodium could survive the welding thermal environment in sufficient quantities to interact with the weld solidification mechanisms and produce a refined structure. They observed that even small additions (0.001 wt\% sodium) were sufficient to enhance eutectic modification over that of rapid cooling produced during welding. Thus, methods utilized by the foundry industry to modify aluminum-silicon eutectic structures could be applied to weld alloys.

While sodium has been shown to be an effective eutectic modifier, its efficacy fades rapidly and can be difficult to control $[28,29]$. Strontium has been identified as a suitable alternative to sodium that is easy to control [29]. Additionally, strontium-modified aluminumsilicon alloys melt easily, are easier to control the eutectic modification, and are more stable than sodium-modified alloys [30]. In comparing the modification effect of sodium versus strontium, Tiedje, et al., observed both elements to be effective modifiers although the sodium-modified alloy exhibited a finer and more uniform structure than the strontium-modified alloy [31]. On average, they also observed strontium additions to increase porosity in cast aluminum-silicon alloys. Lu, et al. studied the combined effect of both sodium and strontium additions in near eutectic aluminum-silicon alloys but did not observe any additional benefit to using two modifiers [30].

Based on the comparative work of sodium and strontium modifications, many researchers have studied the effects and mechanisms responsible for strontium modification of aluminumsilicon alloys (Table 1). While the fundamental mechanisms for strontium modification are not fully understood [22], it has been observed that no significant gains in mechanical properties are observed at strontium additions in excess of approximately $300 \mathrm{ppm}$ in a near-eutectic aluminum-silicon alloy [32]. 
Table 1. Strontium Levels in Hypoeutectic Al-Si Alloys as Reported in the Literature

\begin{tabular}{|c|c|c|}
\hline Si Content (wt\%) & Sr Content (ppm) & Reference \\
\hline 1 & 200 & [33] \\
\hline \multirow{2}{*}{3} & 400 & {$[34,35]$} \\
\hline & $1500-3000$ & [36] \\
\hline \multirow{3}{*}{5} & 150 & [37] \\
\hline & $50-3000$ & {$[38,39]$} \\
\hline & $70-245$ & [40] \\
\hline 6 & $70-245$ & [40] \\
\hline \multirow{8}{*}{7} & 50 & [41] \\
\hline & 150 & [42] \\
\hline & 200 & [40] \\
\hline & 400 & {$[43,34]$} \\
\hline & $70-245$ & [44] \\
\hline & $70-500$ & [22] \\
\hline & $100-150$ & [45] \\
\hline & $250-350$ & [31] \\
\hline \multirow{4}{*}{9} & 200 & [46] \\
\hline & 400 & [47] \\
\hline & $50-200$ & [48] \\
\hline & $200-600$ & [49] \\
\hline \multirow{5}{*}{10} & 150 & [50] \\
\hline & 200 & {$[33,51]$} \\
\hline & 250 & [30] \\
\hline & 290 & [52] \\
\hline & 400 & [34] \\
\hline
\end{tabular}




\begin{tabular}{|c|c|c|}
\hline & $0-1000$ & {$[53]$} \\
& $30-290$ & {$[54]$} \\
& $30-720$ & {$[55]$} \\
& $90-140$ & {$[56]$} \\
& $100-1000$ & {$[32]$} \\
\hline $11-11.7$ & 300 & {$[57]$} \\
& $50-200$ & {$[48]$} \\
& $100-375$ & {$[29]$} \\
\hline $12-12.5$ & 400 & {$[34,35]$} \\
& 1000 & {$[58]$} \\
& $70-245$ & {$[40]$} \\
& $250-350$ & {$[31]$} \\
\hline
\end{tabular}

\subsection{Grain Refinement in Hypoeutectic Aluminum-Silicon Alloys}

Strontium has been observed to be an effective modifier of the eutectic structure of hypoeutectic aluminum-silicon alloys, but can result in enlarged, columnar dendrites which negatively affect mechanical properties [57]. A review of the grain refinement mechanisms proposed for Al-Ti-B additions in aluminum silicon alloys was presented by Easton and St John [59]. Although prior literature debated whether grain nucleation occurred on $\mathrm{TiB}_{2}, \mathrm{AlB}_{2}$, $(\mathrm{Ti}, \mathrm{Al}) \mathrm{B}_{2}$, or $\mathrm{Al}_{3} \mathrm{Ti}$ phases, experimental work performed by Easton and StJohn with aluminum castings provided evidence that grain nucleation occurred on $\mathrm{TiB}_{2}$ phases and the optimum amount of Al-5Ti-1B additions was to $0.05 \mathrm{wt} \% \mathrm{Ti}[59,60]$. The Al-5Ti-1B master alloy has approximately equal atomic ratios of titanium and boron, resulting in an excess of titanium that has been shown to improve the grain refining effect of $\mathrm{TiB}_{2}[59,60]$.

The addition of Al-5Ti-1B to a strontium-modified Al-10Si-0.35Mg alloy was observed to be effective at modifying the eutectic structure while refining grain sizes [61]. Mallapur, et al., also observed improved mechanical properties in an Al-Ti-B grain-refined, strontium-modified A356 aluminum alloy [62]. Murty, et al. observed that at traditional Al-5Ti-1B additions of $0.01 \mathrm{wt} \% \mathrm{Ti}$ in aluminum alloys may be ineffective when silicon is present in the alloy due to a mutual poisoning effect [63]. The poisoning effect could not be fully explained, but Al-5Ti-1B additions in excess of $0.01 \mathrm{wt} \%$ Ti were suggested in the presence of silicon. Lee, et al., observed 
that for high silicon levels (8 wt\% or higher), that no significant reductions in grain size were observed beyond Al-5Ti-1B additions to 0.5wt\% Ti [64].

\subsection{Alloying Considerations for Welding}

The chemistries of aluminum weld alloys are designed to achieve optimal mechanical properties when diluted with a base metal during welding [65]. However, in weld-based 3-D printing, there is no dilution of the weld filler metal with a base metal. The design of an optimal alloy for weld-based 3-D printing must avoid alloying additions that commonly cause cracking in welds (Figure 1) while also having the ability to be printed into a part with good microstructural and mechanical properties with no assistance from dilution [66].

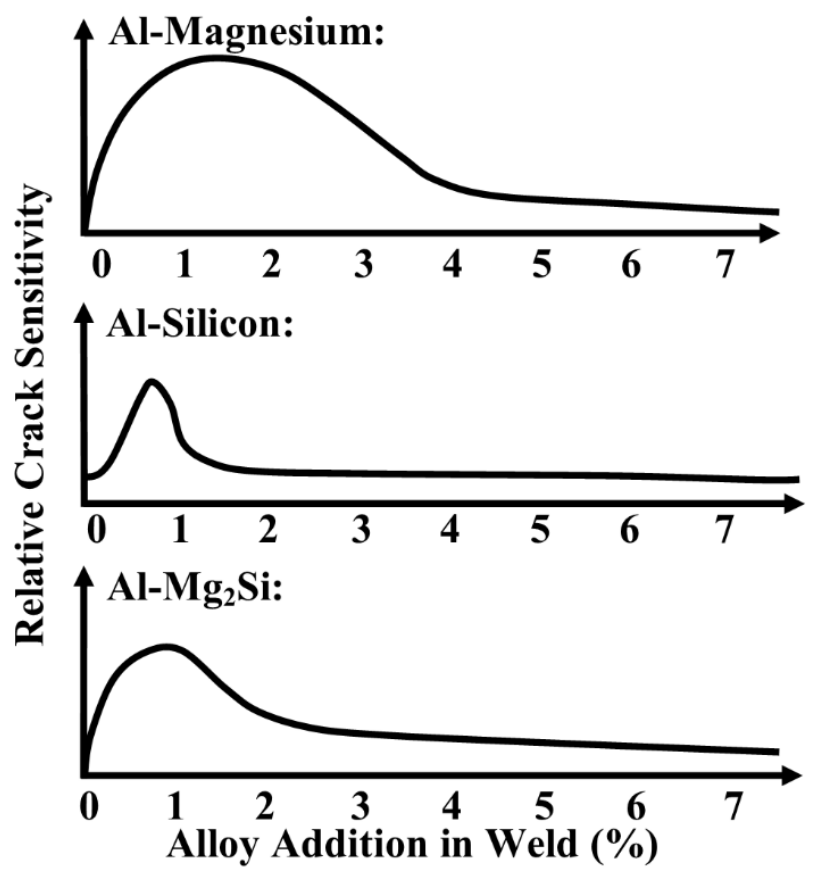

Figure 1. Influence of alloying additions on the weld crack susceptibility in aluminum welds [66].

As solidification range increases, crack susceptibility also increases [18]. Alloying additions that increase the solidification range increase crack susceptibility and should be avoided. By contrast, good starting points for alloy modifications may lie in regions on the phase diagram with short solidification ranges such as compositionally pure and eutectic compositions. Grain refinement, such as adding titanium boride in aluminum alloys, has also been shown to reduce cracking susceptibility [18]. Alloying additions that cause the formation of brittle structures such as aluminum-iron intermetallics or magnesium disilicides can also limit weld performance and should be avoided.

\subsection{The Role of Wedge Castings in Alloy Development}


Wedge-shaped castings are a novel method to evaluate the effect of solidification rate upon mechanical and microstructural properties of aluminum alloys. Caton, et al., evaluated the cracking susceptibility of two aluminum-silicon-copper alloys cast into a wedge shape designed to induce a wide range of solidification rates [67]. Boileau and Allison later used the wedgeshaped mold developed by Caton, et al., to evaluate the influence of solidification rate on the fatigue properties in aluminum-silicon-copper alloys for light-weight vehicle components [68]. Wedge-shaped castings have also allowed researchers to efficiently evaluate the kinetics of microstructural evolution in aluminum-iron-silicon alloys [69], aluminum-magnesium-silicon alloys [70,71], aluminum-manganese alloys [72], aluminum rich alloys alloyed with lanthanide series elements [73], and in metallic glasses [74].

Norman, et al., proposed a wedge casting to evaluate many different amounts of scandium additions to aluminum under a wide range of solidification temperatures [75]. Norman, et al., later extended this work to evaluate scandium's influence on the grain refinement and weldability of 2000 and 7000 series aluminum alloys [76]. In their 2003 study, Norman, et al., successfully cast aluminum-scandium alloys at solidification rates comparable to those observed in fusion welding. The approach of Norman, et al., to evaluate the influence of alloying elements on weldability, was extended to this study to screen several alloy modifications for GMAWbased 3-D printing [76]. By matching solidification rates in appropriate casting experiments with those in GMAW additive manufacturing, alloys can be rapidly screened for optimal properties in 3-D printing. Common modifiers to aluminum-silicon alloys, strontium and titanium boride, were evaluated for their ability to reduce porosity and further increase ductility of 4047 and 4943 3-D printed materials. The results are discussed in the context of low cost GMAW-based 3-D metal printing.

\section{Materials \& Methods}

\subsection{Description of Permanent Mold}

The permanent mold used in this study was a wedge shaped casting modified from Norman, et al. (Figure 2) [75]. 

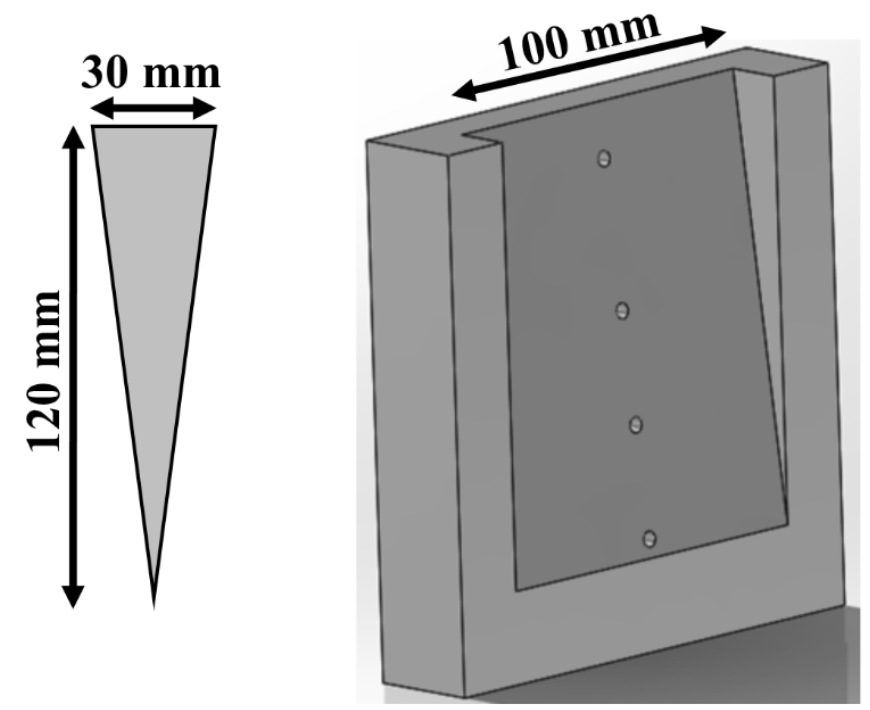

Figure 2. Schematic drawings of the wedge casting and permanent mold. Wedge profile (left) and the modified permanent mold (right).

This mold was chosen as it could induce a wide range of cooling rates, allowing for comparisons between cast alloys and 3-D printed alloys. The mold was machined from two 99.00\% copper bars. Four holes for thermocouple insertion were located in the side to allow for cooling rate measurement from the centerline of the wedge while minimizing the length of thermocouple within the mold. The holes were $2.25 \mathrm{~mm}$ in diameter to provide a tight fit for the Type $\mathrm{K}$ thermocouples with a protective stainless steel sheath ( $0.25 \mathrm{~mm}$ wall thickness).

\subsection{Alloy Melting \& Pouring}

Eleven alloys based upon 4047 (approximately $11.6 \mathrm{wt} \% \mathrm{Si}$ ) and 4943 (with approximately $5.5 \mathrm{wt} \% \mathrm{Si}$ and $0.3 \mathrm{wt} \% \mathrm{Mg}$ ) were analyzed in this study (Table 2). Additions of magnesium, strontium, titanium boride, and combinations thereof were evaluated for the influence on the microstructural and mechanical properties of aluminum-silicon alloys similar to 4047 and 4943.

Table 2. Target Compositions of Experimental Alloys. All values given in wt\%.

\begin{tabular}{|c|c|c|c|c|}
\hline $\mathbf{S i}$ & $\mathbf{M g}$ & $\mathbf{S r}$ & $\mathbf{T i}$ & $\mathbf{A l}$ \\
\hline $10.8-12.4$ & - & - & - & Bal. \\
\hline $10.8-12.4$ & $0.2-0.5$ & - & - & Bal. \\
\hline $10.8-12.4$ & $0.2-0.5$ & $0.02-0.04$ & - & Bal. \\
\hline $10.8-12.4$ & $0.2-0.5$ & - & $0.04-0.06$ & Bal. \\
\hline $10.8-12.4$ & - & $0.02-0.04$ & $0.04-0.06$ & Bal. \\
\hline $10.8-12.4$ & $0.2-0.5$ & $0.02-0.04$ & $0.04-0.06$ & Bal. \\
\hline $5-6$ & $0.2-0.5$ & - & - & Bal. \\
\hline $5-6$ & $0.2-0.5$ & $0.02-0.04$ & - & Bal. \\
\hline
\end{tabular}




\begin{tabular}{|c|c|c|c|c|}
\hline $5-6$ & $0.2-0.5$ & - & $0.04-0.06$ & Bal. \\
\hline $5-6$ & - & $0.02-0.04$ & $0.04-0.06$ & Bal. \\
\hline $5-6$ & $0.2-0.5$ & $0.02-0.04$ & $0.04-0.06$ & Bal. \\
\hline
\end{tabular}

Charge materials consisting of 99.999\% pure aluminum and Al-36wt\%Si were preheated in a silica crucible in a resistance box furnace for 1 hour at $300^{\circ} \mathrm{C}$ to drive off any oils or organic materials that could increase porosity in the melt. Following this preheat, the crucible and preheated charge material were moved into a Thermolyne type 46200 high temperature furnace. This furnace had two argon gas inlets: One directly to the top of the melt surface and one in the bottom of the furnace. 99.999\% pure argon gas was flowed through both gas inlets at approximately $0.05 \mathrm{~L} / \mathrm{sec}$. No active degassing, in which inert gas is bubbled through the melt, was performed since the metal was melted in an inert atmosphere.

Once molten, the crucible was pulled out of the furnace and the melt was stirred thoroughly with a stainless steel probe prior to pouring a small button for chemical verification via optical emission spectrometry (OES). The button surface was ground smooth with a lathe. A minimum of three burns were used to verify alloy chemistry. Alloy chemistries were monitored and corrected for silicon, iron, magnesium, titanium, boron, and strontium levels

A boron nitride coated stainless steel cup was used to collect an approximately $120 \mathrm{~mL}$ specimen. The cup was placed in an insulating support and a thermocouple was inserted into the center of the melt for cooling rate analysis. A second OES button and the first wedge casting were poured. No active degassing was performed since we melted in a closed, relatively inert (Ar) environment. Once the specimens were cool, the remaining two wedges and a third OES button were poured. A third OES button was poured after the third wedge to verify the initial wedge chemistry and the final wedge chemistry were within the target range (Table 3).

Table 3. Actual Compositions of Experimental Alloys. All values given in wt\%.

\begin{tabular}{|c|c|c|c|c|}
\hline Si & $\mathbf{M g}$ & Sr & Ti & Al \\
\hline 12.1 & - & - & - & Bal. \\
\hline 11.5 & 0.3 & - & - & Bal. \\
\hline 11.3 & 0.3 & 0.027 & - & Bal. \\
\hline 11.2 & 0.3 & - & 0.053 & Bal. \\
\hline 11.3 & - & 0.028 & 0.053 & Bal. \\
\hline 11.4 & 0.3 & 0.025 & 0.057 & Bal. \\
\hline 6 & 0.3 & - & - & Bal. \\
\hline 5.7 & 0.3 & 0.023 & - & Bal. \\
\hline 5.5 & 0.3 & - & 0.055 & Bal. \\
\hline 5.6 & - & 0.029 & 0.050 & Bal. \\
\hline 5.5 & 0.3 & 0.031 & 0.040 & Bal. \\
\hline
\end{tabular}




\subsection{Alloy Testing \& Analysis} (Figure 3).

One wedge of each alloy was sectioned into four pieces for microstructural analysis

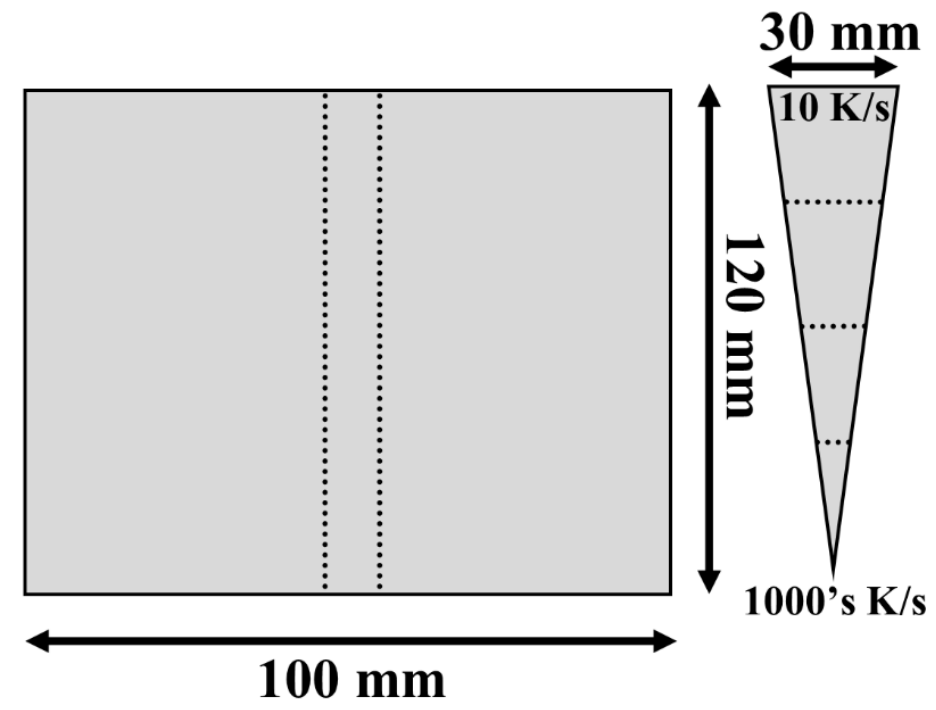

Figure 3. Schematic drawing of the wedge castings with dashed lines to represent cut sections.

The sections were mounted in epoxy, polished to $0.05 \mu \mathrm{m}$ silica, and etched using Keller's reagent for 30 seconds. Secondary dendrite arm spacing (SDAS) was measured across three or more secondary dendrite arms in an edge-to-edge fashion using ImageJ software [77]. The SDAS was calculated by a simple ratio of dendrite length (L) over total number of secondary dendrite arm spaces $(\mathrm{N})$ (Equation 1).

$$
S D A S=\frac{L}{N}
$$

A cooling rate could subsequently be calculated for this SDAS given a fitting factor (B) for a specific alloy and a constant (n) (Equation 2).

$$
\text { Cooling Rate }=\left(\frac{S D A S}{B}\right)^{-1 / n}
$$

For 4043 aluminum, $\mathrm{B}=50 \mu \mathrm{m}\left(\mathrm{Ks}^{-1}\right)^{\mathrm{n}}$ and $\mathrm{n}=0.33$, a unitless number $[78,79]$. Heard, et al. found agreement between calculated and experimental data when these 4043 aluminum constants were applied to 4047 aluminum [80]. The same computational approach was applied to this study to evaluate the cooling rates in modified Al-5.5\%Si-0.4\%Mg and Al-11.6\%Si alloys. This analysis indicated that the 7-12 $\mathrm{mm}$ SDAS corresponding to approximately $250 \mathrm{~K} / \mathrm{sec}$ cooling rates reported for 3-D printed specimens was in the region approximately $25-50 \mathrm{~mm}$ above the cast wedge tip and close to the wedge sides [21]. These cooling rates could not be verified using 
the more traditional method using cast thermal modeling software Magma. Magma could not model solidification in the wedge tip due its small geometry; the generated mesh elements could not fully span the wedge tip geometry and in some instances thin walled elements formed. Thin walled elements are undesirable in Magma, which uses a finite volume method, because they have a small connection with the rest of the part which affects the calculated thermal transfer.

Two subsize rectangular tensile specimens were machined from the remaining wedges, providing four total tensile specimens per alloy (Figure 4) [81].

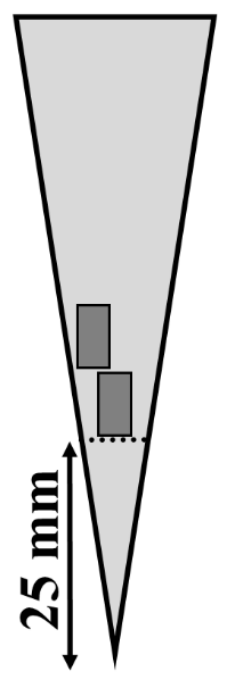

Figure 4. Schematic drawing showing the approximate origin of tensile bars.

Prior to tensile testing, the internal (closed) porosity of the tensile specimens was measured using the Archimedes' method as described previously [20]. Tensile specimens were pulled to failure at a strain rate of $10^{-3} \mathrm{sec}^{-1}$ according to ASTM B557 as described previously [21]. Only specimens that broke within the gauge section were used for further analysis.

\section{Results}

\subsection{Microstructural \& Thermal Analysis}

The unmodified high-silicon alloy and the high-silicon alloys modified with magnesium and titanium boride exhibited primary silicon precipitates near to or surrounded by primary aluminum dendrites (Figure 5). Alloys modified with strontium exhibited a cleaner and more refined microstructure. 


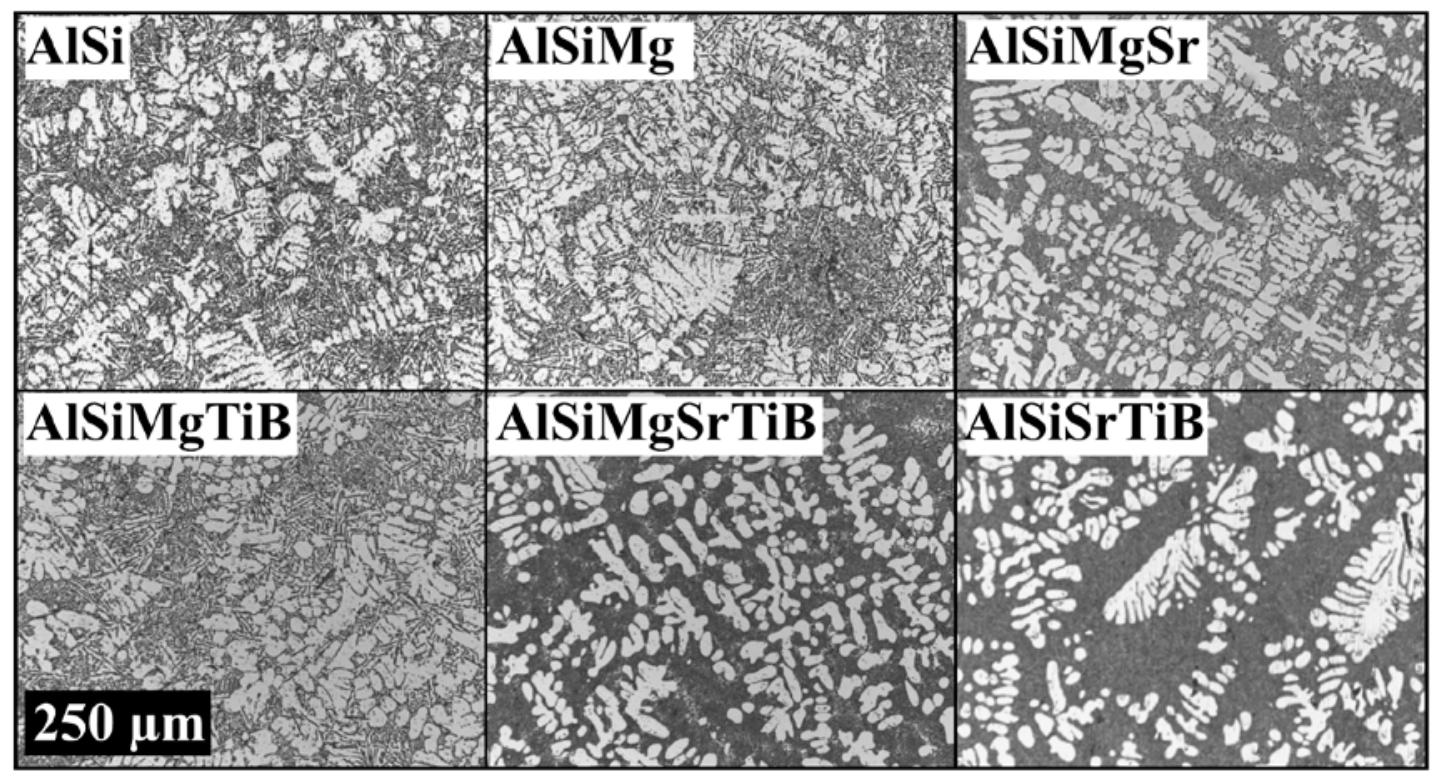

Figure 5. Comparative microstructures of the high-silicon alloys. Scale bar represents $250 \mu \mathrm{m}$ in all images.

The eutectic structure of alloys not containing strontium was coarse and consisted of flakes with sharp edges (Figure 6). The addition of strontium significantly refined the eutectic structure of the high-silicon alloys in terms of overall size and length. Strontium also rounded the eutectic edges. Alloys containing both strontium and titanium boride exhibited a finer eutectic structure than alloys only modified with strontium However, the combination of strontium and titanium boride allowed aluminum growth in the magnesium containing alloy but this aluminum growth less pronounced in the strontium-titanium boride alloy that did not contain magnesium.

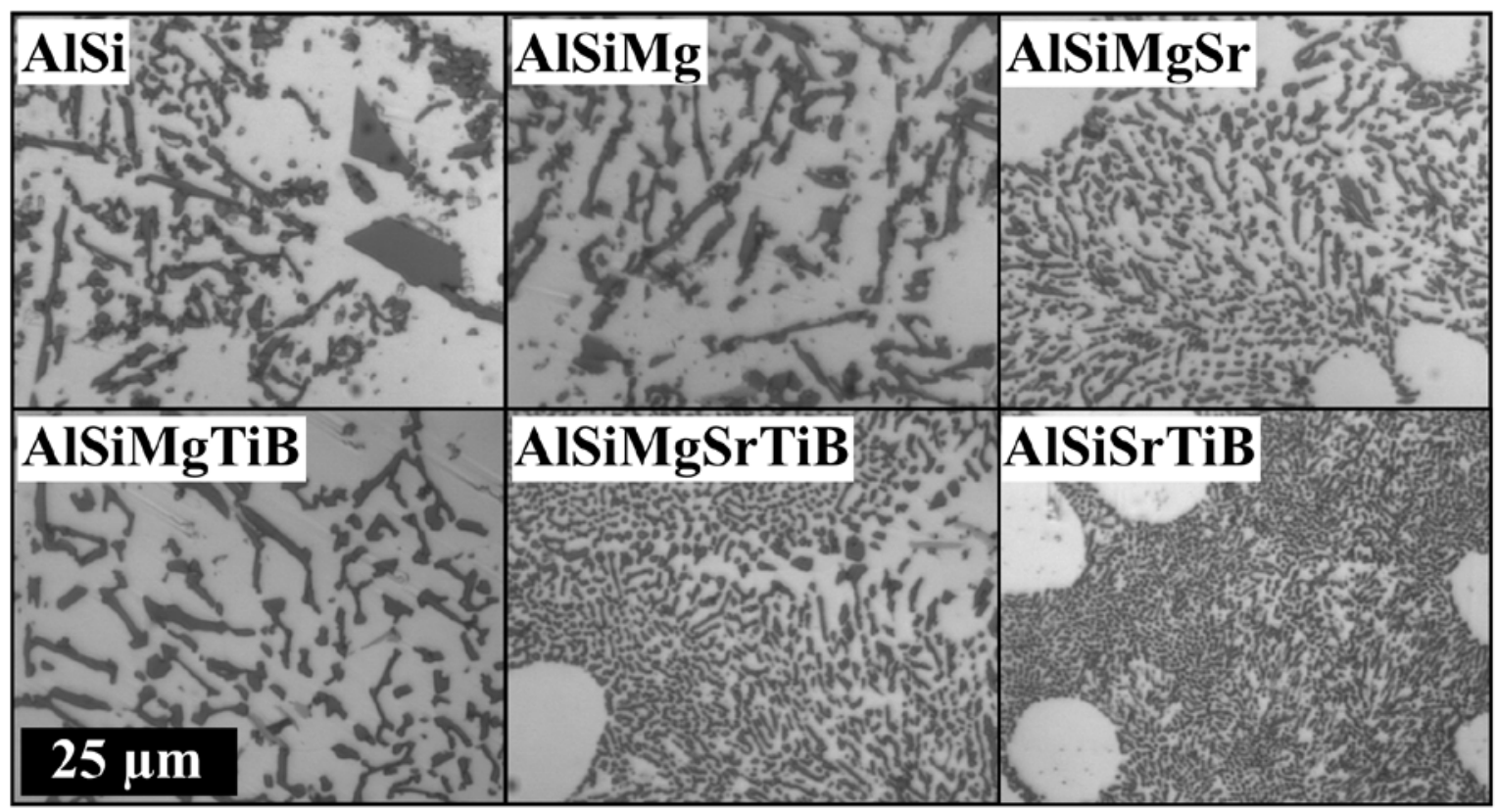


Figure 6. Comparative eutectic microstructures of the high-silicon alloys. Scale bar represents $25 \mu \mathrm{m}$ in all images.

Few differences were observed in the microstructure of the low-silicon alloy (Figure 7). The dendritic and eutectic structures of the Al-5.5Si-0.03Sr-0.05TiB alloy appeared to be more refined than in the other low-silicon alloys. Additionally, the eutectic phase appeared to form larger colonies in the Al-5.5Si-0.03Sr-0.05TiB alloy than in the other alloys.
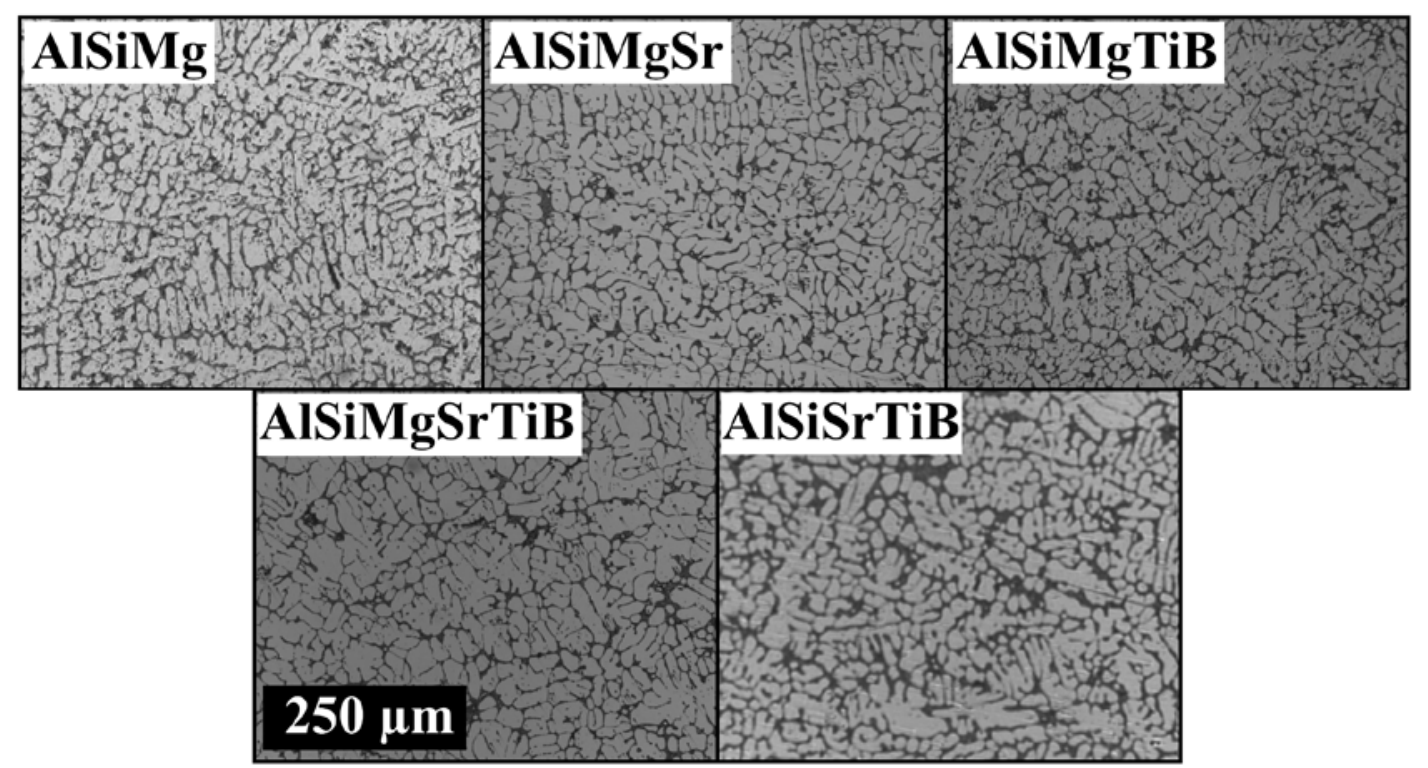

Figure 7. Comparative microstructures of the low-silicon alloys. Scale bar represents $250 \mu \mathrm{m}$ in all images.

No significant differences were observed upon closer examination of the low-silicon alloy eutectic phases (Figure 8). The eutectic structures of all alloys appeared to be small and with rounded edges, similar to the strontium modified high-silicon alloys. 

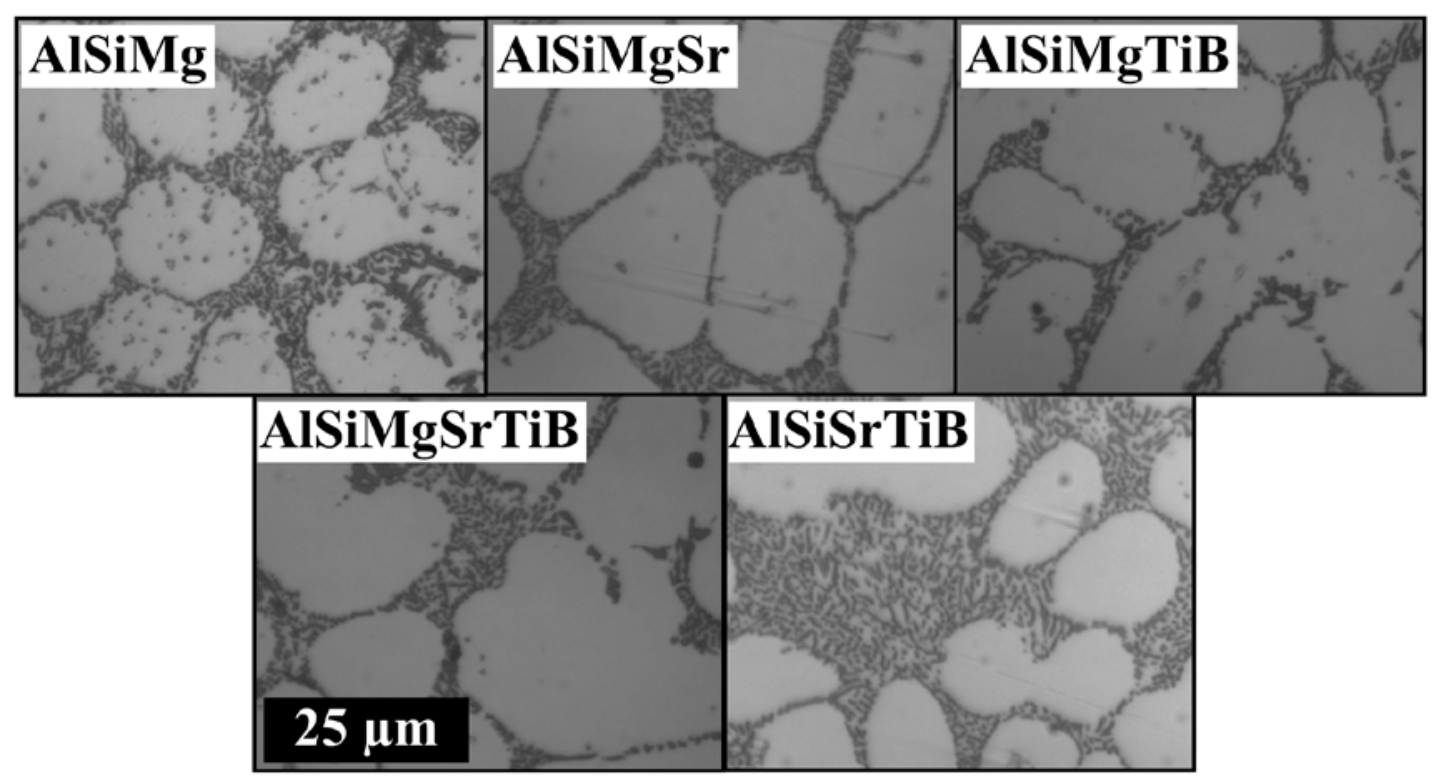

Figure 8. Comparative eutectic microstructures in the low-silicon alloys. Scale bar represents $25 \mu \mathrm{m}$ in all images.

The low-silicon alloys exhibited larger solidification ranges than the high-silicon alloys (Figure 9). The low-silicon alloys also exhibited lower eutectic growth temperatures and shorter eutectic growth times than the high-silicon alloys (Figure 10). All modifications decreased the eutectic growth temperature of the high-silicon alloy, whereas titanium boride additions increased the eutectic growth temperature of the low-silicon AlSiMg alloy. Strontium additions decreased eutectic growth temperatures more than any other alloying modification. In the highsilicon alloy, there was almost no difference in the cooling response of the magnesium-titanium boride alloy and the strontium-titanium boride alloy, and these curves could not be distinguished from one another. 

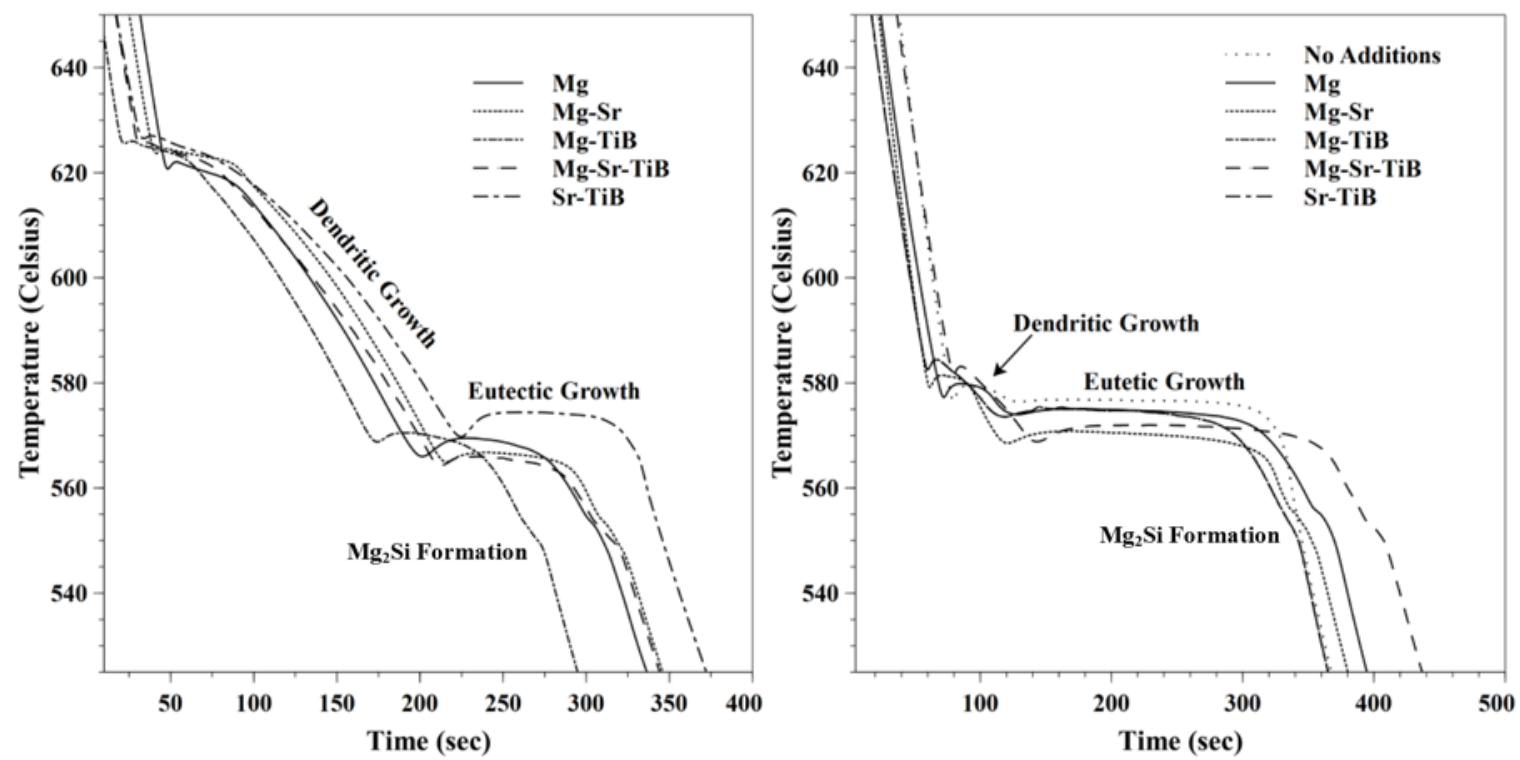

Figure 9. Cooling curves of cast alloys. Al-5.5\% Si alloys (left) and Al-11.6\% Si alloys (right). They are separated for clarity.

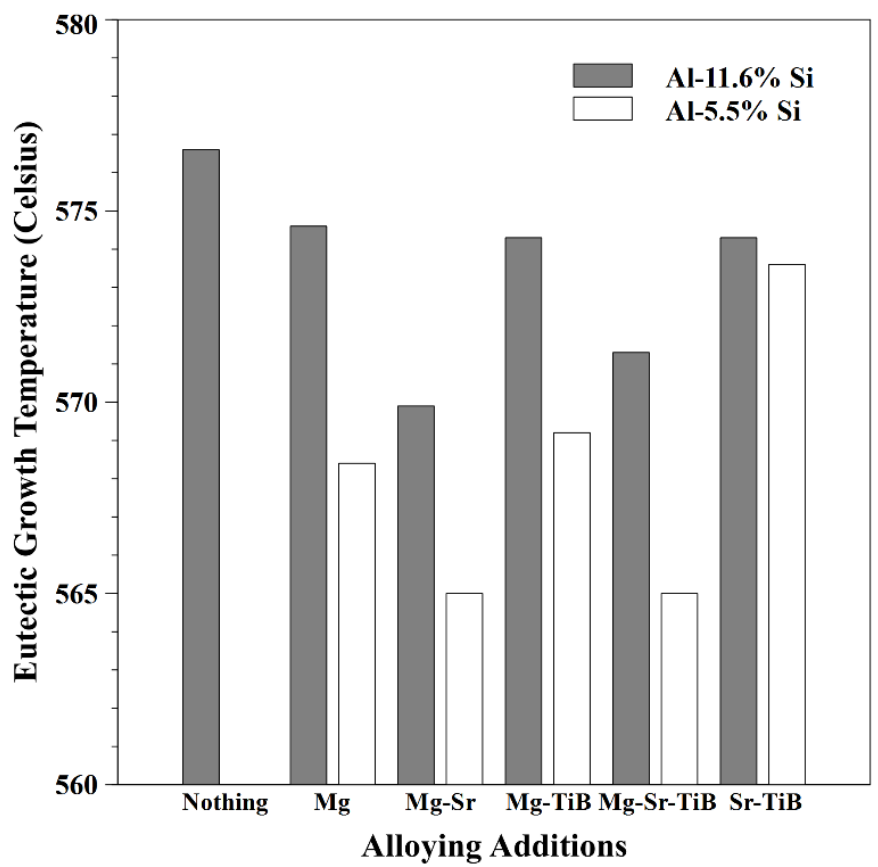

Figure 10. Eutectic growth temperature of cast alloys.

All alloys exhibited porosity of $0.4 \%$ or less (Figure 11 ). The porosity of the low-silicon alloy was lower than that for the high-silicon alloy. Additions of strontium or titanium boride to 
magnesium-containing alloys increased porosity levels, although porosity levels significantly decreased when both strontium and titanium boride were added to magnesium-containing alloys.

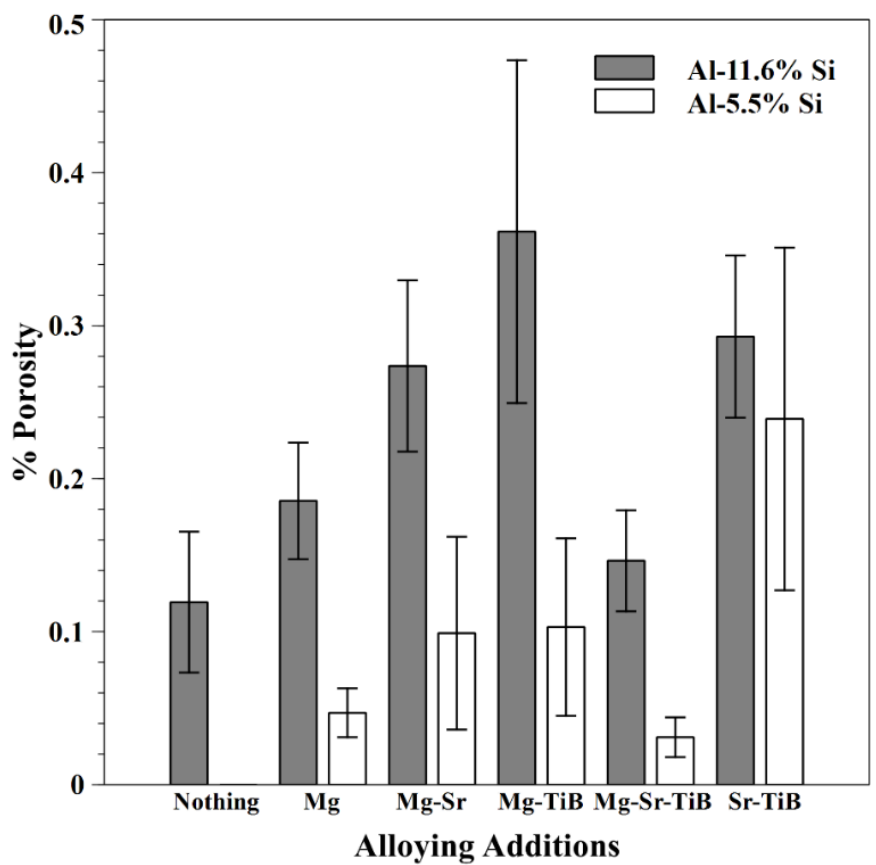

Figure 11. Average porosity of the cast experimental alloys. Error bars represent \pm 2 standard error (nominally 95\% confidence intervals).

\subsection{Mechanical Properties}

Few significant differences were observed in the yield strengths of either aluminumsilicon alloy (Figure 12). Any modification to the high-silicon alloy (magnesium, strontium, and/or titanium boride) significantly increased the yield strength. Low-silicon alloys containing magnesium exhibited higher yield strengths than the low-silicon that did not contain magnesium. There were no differences in the yield strengths of the high or low-silicon alloys that contained magnesium. 


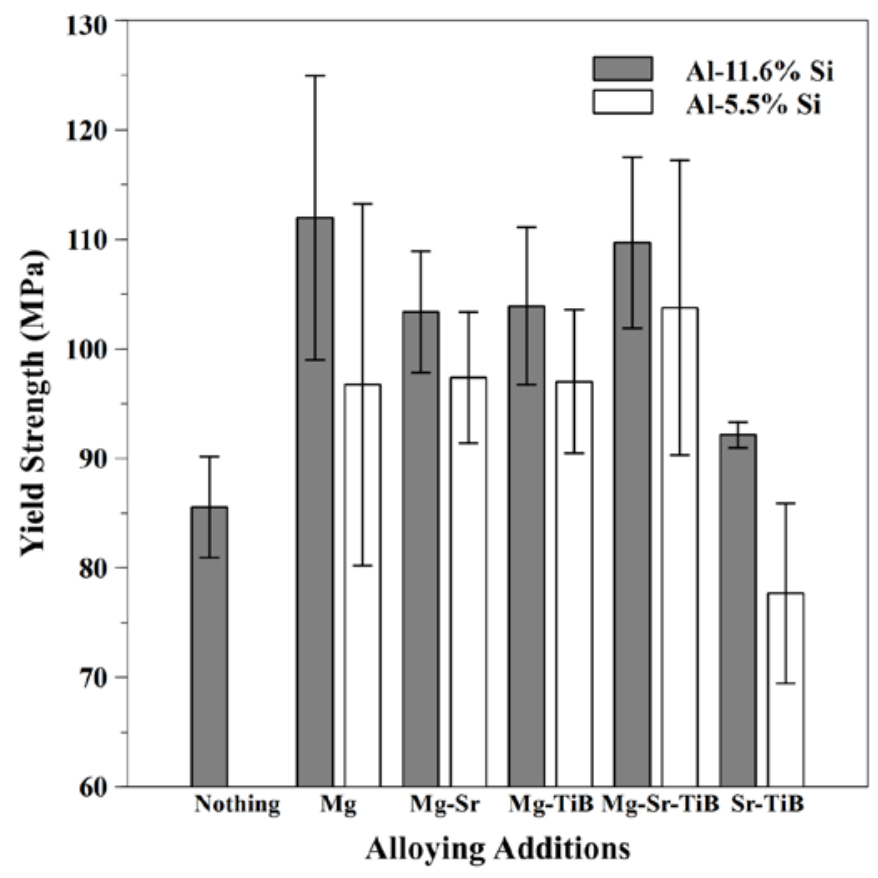

Figure 12. Average $0.02 \%$ offset yield strength of the cast experimental alloys. Error bars represent \pm 2 standard error.

The additions of magnesium-strontium, magnesium-strontium-titanium boride, and strontium-titanium boride provided the highest ultimate tensile strength in the high-silicon alloy (Figure 13). The low-silicon magnesium, magnesium-strontium, and magnesium-titanium boride alloys exhibited higher ultimate tensile strengths than their high-silicon counterparts. In contrast, the high-silicon strontium-titanium boride alloy had a higher ultimate tensile strength than its low-silicon counterpart. The low-silicon alloys exhibited greater ductility (\% elongation) and greater variability in their performance than the high-silicon alloys (Figure 13). Magnesium additions worsened the ductility of high-silicon alloys, although ductility could be recovered with strontium additions. Titanium boride worsened the ductility of magnesium-containing lowsilicon alloys. On average, the strontium-titanium boride alloys exhibited the greatest ductility when magnesium was not present. 

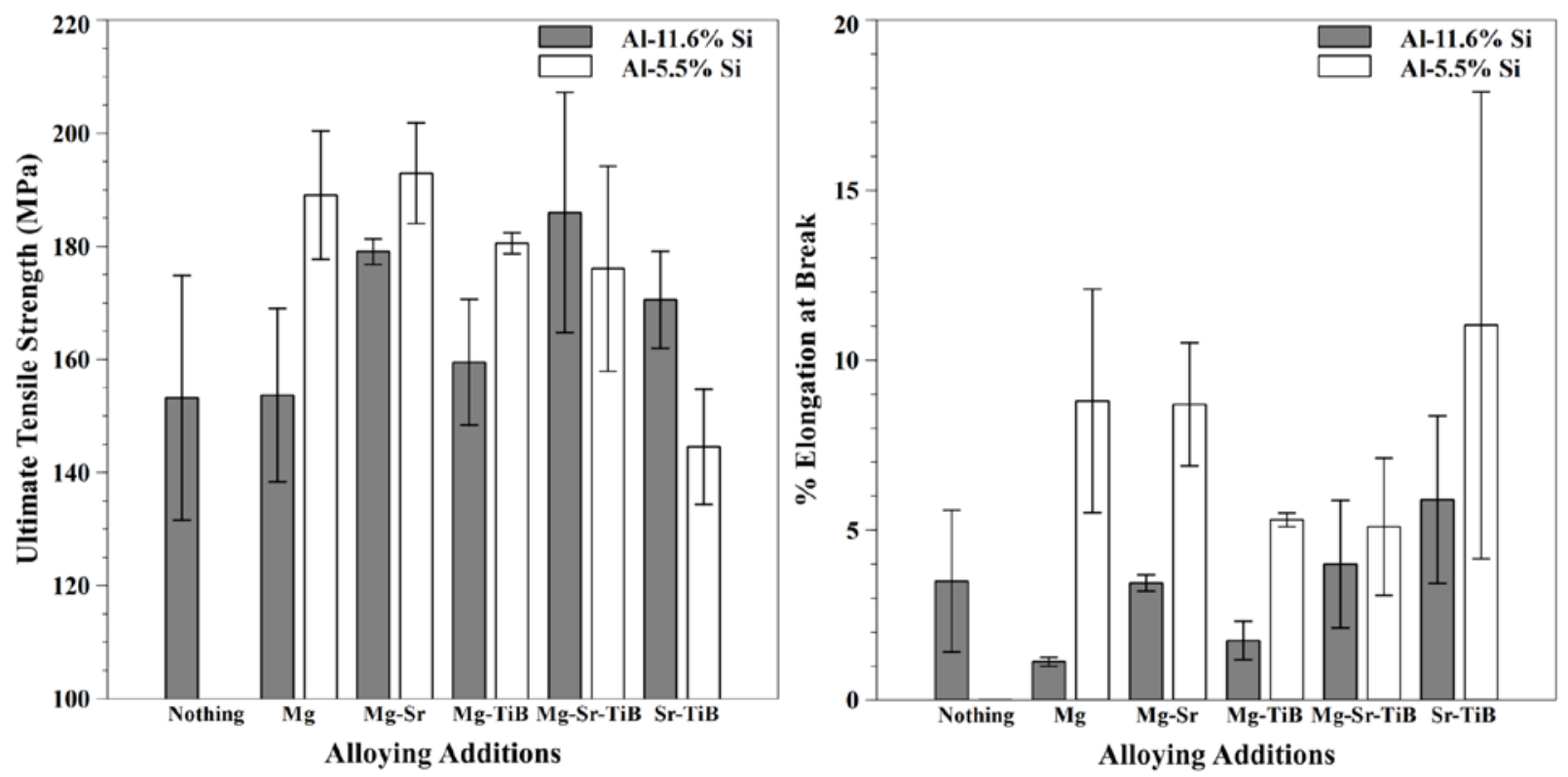

Figure 13. Average ultimate tensile strength (left) and elongation at break (right) of the cast experimental alloys. Error bars represent \pm 2 standard error.

\section{Discussion}

No significant differences were observed in the microstructures of the low-silicon alloys. Therefore, large differences in mechanical properties were not anticipated or observed. The short eutectic growth time in the low-silicon alloys resulted in a fine silicon eutectic structure. A reduction in the size and aspect ratio of silicon particles in aluminum-silicon particles has been previously reported with faster cooling rates [82]. Magnesium additions to aluminum-silicon alloys results in solid solution strengthening, explaining why the Al-5.5Si-Sr-TiB alloy exhibited lower yield and ultimate tensile strengths than magnesium-containing alloys.

The depression in eutectic temperature with magnesium additions has been reported by Heusler and Schneider [48]. They observed a magnesium addition of $0.35 \mathrm{wt} \%$ in an $\mathrm{Al}-11 \mathrm{Si}$ alloy to reduce the eutectic temperature from $577^{\circ} \mathrm{C}$ to approximately $575^{\circ} \mathrm{C}$. This same trend was observed in this study upon the addition of $0.3 \mathrm{wt} \%$ magnesium to an Al-11.6Si alloy. Heusler and Schneider also observed a decrease in eutectic temperature upon the addition of strontium [48]. The depression in eutectic temperature was observed in strontium-modified Al10Si alloys that did not contain magnesium [22,55]. This depression in eutectic growth temperature increases the nucleation driving force and growth velocity, allowing for faster nucleation of the modified eutectic structure [55]. A single accepted explanation for the decrease in eutectic temperature with the addition of modifying elements does not exist. However, it has been proposed that a decrease in eutectic temperature indicates an increase in the difficulty and location of eutectic nucleation [22]. An additional transformation was observed in the 
magnesium-containing alloys at approximately $555^{\circ} \mathrm{C}$, corresponding to the formation of $\mathrm{Mg}_{2} \mathrm{Si}$ phases (Figure 9) [83].

The higher porosity in the high-silicon alloys limited mechanical properties such as ultimate tensile strength and ductility. Porosity was observed in the fracture surfaces of the highsilicon alloys, particularly the alloys containing MgSrTiB, MgTiB, and SrTiB additions. Pores act as stress concentrators and can cause materials to prematurely fail in tension. It was originally expected that the low-silicon alloy would exhibit higher porosity due to lack of interdendritic feeding between closely spaced dendrites [84]. In fact, porosity in fracture surfaces of the lowsilicon alloys was almost nonexistent. It was observed during melting that there was interaction between the aluminum-silicon melt and the silica crucibles and this reaction increased with increasing silicon levels in the melt. These silica levels could contribute to porosity by allowing for heterogeneous nucleation of pores. Magnesium oxidizes easily and magnesium oxide additions can also contribute to porosity by serving as heterogeneous nucleation sites for pores [85]. Thus, it was expected that magnesium-containing high-silicon alloys would exhibit higher porosities than the alloy without magnesium.

There were few differences among the yield and ultimate tensile strengths of the experimental alloys studied. All modified high-silicon alloys exhibited greater yield strengths than the non-modified alloy. The high and low-silicon alloys benefited from magnesium additions as the Al-Si-Sr-TiB alloys exhibited lower yield strengths. There were no significant differences in ultimate tensile strengths among the high-silicon alloy. The low-silicon Al-Si-SrTiB alloy that did not contain magnesium exhibited lower ultimate tensile strength than its magnesium-containing counterparts.

There were also few differences in total elongation amongst the alloys. The addition of strontium to a high-silicon alloy with magnesium increased ductility. In aluminum-silicon alloys, ductility is limited by cracking of the silicon eutectic particles [86]. Wang, et al., observed that cracking in A356 and A357 cast aluminum alloys was most prominent in silicon particles with large aspect ratios, limiting tensile properties [82,86]. Modification of A356 and A357 cast aluminum alloys with strontium was observed to decrease the overall size and aspect ratio of the silicon eutectic particles [82]. The smaller, sphere-like silicon particles limited stress concentration and cracking, ultimately leading to greater ductility in the alloy [86]. The lowsilicon alloys exhibited greater elongation at break than the high-silicon alloys, except when strontium and titanium boride were added to the alloys.

A quality index can be used as a method to quantify and compare the quality of different alloys and processes using ultimate tensile strength (UTS) and percent elongation (\%E) (Equation 3) [87, 88].

$$
\text { Quality Index }(\mathrm{MPa})=\text { UTS }+\left(150 * \log _{10} \% E\right)
$$

The low-silicon alloys exhibited higher quality indexes on average than the high-silicon alloys (Figure 14). However, the high-silicon alloy containing titanium boride and strontium additions, with and without magnesium, exhibited quality indexes that were statistically equivalent to the 
low-silicon alloys. Although magnesium acts as a solid solution strengthener increasing UTS, it can decrease elongation and ductility which is undesirable.

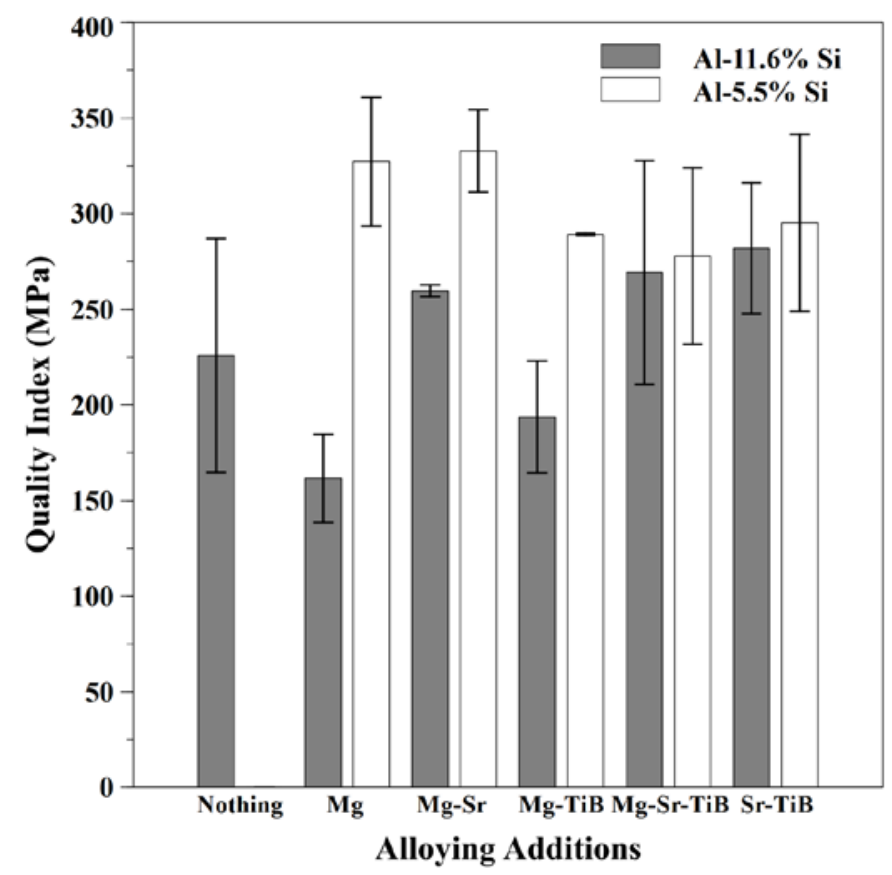

Figure 141. Calculated quality index for each experimental alloy. Error bars represent \pm 2 standard error.

The wedge casting approach was a convenient approach to rapidly screen alloying additions in feedstock for weld-based 3-D printing. However, this approach does not fully account for the unique thermal environment of weld-based 3-D printing. For instance, during the deposition of new weld layers, the previous layers are reheated when exposed to the high temperature metal. This thermal environment can have significant impact upon 3-D printed part properties. Further work is necessary to evaluate the performance of these modified aluminumsilicon alloys in a 3-D printed part. This the wedge casting approach to screen alloying elements may be beneficial to other industries. For metal parts with complex geometries and solidification rates, wedge castings may be a simple and rapid first step to screen alloying additions. Alternatively, wedge castings could be used to evaluate the effect of cooling rate of a particular alloy to determine if more or less cooling may benefit the cast or 3-D printed part.

\section{Conclusions}

In order to develop an easy-to-print aluminum alloy, previous work indicated that 4047 and 4943 weld alloys may benefit the most from further alloying modifications. Wedge-shaped castings were used to screen alloying additions to 4047 and 4943-based weld alloys to improve mechanical properties such as ductility and to redistribute porosity. Wedge-shaped castings allowed researchers to induce the same solidification rates during casting as during weld-based 
3-D printing. The addition of magnesium, strontium, titanium boride, and combinations thereof were evaluated for their influence on microstructural and mechanical properties.

The modified high-silicon alloy (4047) exhibited the greatest change in microstructure whereas the modified low-silicon alloy (4943) did not exhibit changes in microstructure after modification. Strontium was observed to be an effective eutectic-modifier in the high-silicon alloy. The combination of strontium and titanium boride in the high-silicon alloys produced the finest eutectic structure. Higher porosity levels limited the mechanical properties of the highsilicon alloy. However, the alloys containing both strontium and titanium boride without the presence of magnesium exhibited the greatest ductility on average. Future work should evaluate the singular effects of strontium, titanium boride, and the combination of strontium and titanium boride in weld-based 3-D printing.

\section{Acknowledgments}

The authors wish to acknowledge valuable casting and chemical analysis assistance from P. Quimby, polishing assistance from V. Thole, and helpful discussions with Dr. Stephen Kampe and Dr. Thomas Dorin. The authors would also like to acknowledge support and helpful discussions with C. Hsu and technical assistance from the Miller Electric Manufacturing Company. This material is based on research sponsored by Air Force Research Laboratory under agreement number FA8650-12-2-7230. The U.S. Government is authorized to reproduce and distribute reprints for Governmental purposes notwithstanding any copyright notation thereon. The views and conclusions contained herein are those of the authors and should not be interpreted as necessarily representing the official policies or endorsements, either expressed or implied, of Air Force Research Laboratory or the U.S. Government.

\section{Author Disclosure Statement}

No conflicts of interest exist.

\section{References}

1. Murr, L. E., Martinez, E., Amato, K. N., Gaytan, S. M., Hernandez, J., Ramirez, D. A., ... \& Wicker, R. B. (2012a). Fabrication of Metal and Alloy Components by Additive Manufacturing: Examples of 3D Materials Science. Journal of Materials Research and Technology. 1(1): 42-54.

2. Wohlers, T., \& Caffrey, T. (2014). Wohlers Report 2014 Annual Worldwide Progress Report. Wohlers Associates, Inc. Fort Collins, CO. 
3. Frazier, W. E. (2014). Metal Additive Manufacturing: A Review. Journal of Materials Engineering and Performance. 23(6), 1917-1928.

4. Horn, T. J., \& Harrysson, O. L. A. (2012). Overview of current additive manufacturing technologies and selected applications. Science Progress. 95(3): 255-282.

5. Wohlers, T., \& Caffrey, T. (2015). Wohlers Report 2015 Annual Worldwide Progress Report. Wohlers Associates, Inc. Fort Collins, CO.

6. Murr, L. E., Gaytan, S. M., Ramirez, D. A., Martinez, E., Hernandez, J., Amato, K. N., ... \& Wicker, R. B. (2012b). Metal Fabrication by Additive Manufacturing Using Laser and Electron Beam Melting Technologies. Journal of Materials Science \& Technology. 28(1): $1-14$.

7. Taminger, K. M. B., \& Hafley, R. A. (2003). Electron Beam Freeform Fabrication: A Rapid Metal Deposition Process. Presented at the 3rd Annual Automotive Composites Conference, Troy, MI: Society of Plastics Engineers, Inc.

8. Kruth, J. P. (1991). Material incress manufacturing by rapid prototyping techniques. CIRP Annals-Manufacturing Technology. 40(2): 603-614.

9. Peels, J. (23 May 2014). Metal 3D printing: From lab to fab. Inside 3DP. http:// www.inside3dp.com/ metal-3d-pinting-lab-fab/, last accessed 22 March 2016.

10. Anzalone G. C., Zhang C., Wijnen B., Sanders, P. G., Pearce, J. M. (2013). A low-cost opensource metal 3-D printer. IEEE Access, 1: 803-810.

11. Pinar, A., Wijnen, B., Anzalone, G.C., Havens, T.C., Sanders, P.G. and Pearce, J.M., 2015. Low-cost open-source voltage and current monitor for gas metal arc weld 3D printing. Journal of Sensors. Article ID 876714, 2015. doi:10.1155/2015/876714

12. Nilsiam, Y., Haselhuhn, A., Wijnen, B., Sanders, P. and Pearce, J.M., 2015. Integrated Voltage-Current Monitoring and Control of Gas Metal Arc Weld Magnetic Ball-Jointed Open Source 3-D Printer. Machines, 3(4), pp.339-351.

13. Wijnen, B., Anzalone, G.C., Haselhuhn, A.S., Sanders, P.G. and Pearce, J.M., 2016. Free and open-source control software for 3-D motion and processing. Journal of Open Research Software, 4(1). 4: e2, DOI: http://dx.doi.org/10.5334/jors.78

14. Sciaky, Inc. (2016). Advantages of wire AM vs. Powder AM. http://www.sciaky.com/ additive-manufacturing/wire-am-vs-powder-am, last accessed 22 March 2016.

15. Ujiie, A. (1972). U.S. Patent No. 3,665,143. (Published May 23, 1972). Washington, DC: U.S. Patent and Trademark Office. 
16. Brandi, H. T., \& Luckow, H. (1976). U.S. Patent No. 3,985,995. (Published October 12, 1976). Washington, DC: U.S. Patent and Trademark Office.

17. Ding, D., Pan, Z., Cuiuri, D., \& Li, H. (2015). A multi-bead overlapping model for robotic wire and arc additive manufacturing (WAAM). Robotics and Computer-Integrated Manufacturing. 31: 101-110.

18. Lancaster, J. F. Metallurgy of Welding; 1993. London, Chapman \& Hall.

19. Haselhuhn, A. S., Gooding, E. J., Glover, A. G., Anzalone, G. C., Wijnen, B., Sanders, P. G., \& Pearce, J. M. (2014). Substrate release mechanisms for gas metal arc weld 3D aluminum metal printing. 3D Printing and Additive Manufacturing, 1(4), 204-209.

20. Haselhuhn, A. S., Wijnen, B., Anzalone, G.C., Sanders, P.G., \& Pearce, J.M. (2015). In situ formation of substrate release mechanisms for gas metal arc weld metal 3-D printing. Journal of Materials Processing Technology, 226, 50-59.

21. Haselhuhn, A.S., Buhr, M.W., Wijnen, B., Sanders, P.G., \& Pearce, J.M. (2016). Structureproperty relationships of common aluminum weld alloys utilized as feedstock for GMAW-based 3-D printing. Materials Science \& Engineering: A, 673: 511-523.

22. Dahle, A. K., Nogita, K., McDonald, S. D., Dinnis, C., \& Lu, L. (2005). Eutectic modification and microstructure development in Al-Si Alloys. Materials Science and Engineering: A. 413-414: 243-248.

23. Pacz, A. (1920). U.S. Patent No. 1387900A. (Published August 16, 1921). Washington, DC: U.S. Patent and Trademark Office.

24. Flood, S. C., \& Hunt, J. D. (1981). Modification of Al-Si eutectic alloys with Na. Metal Science. 15(7): 287-294.

25. Cross, C. E., \& Olson, D. L. (1982). Modification of Eutectic Weld Metal Microstructure. Welding Journal. 61: 381s-387s.

26. Lu, S.-Z., and A. Hellawell. (1987). The Mechanism of Silicon Modification in AluminumSilicon Alloys: Impurity Induced Twinning. Metallurgical Transactions A. 18(10): 172133.

27. Qiyang, Liu, Li Qingchun, and Liu Qifu. (1991). Modification of Al-Si Alloys with Sodium. Acta Metallurgica et Materialia. 39(11): 2497-2502.

28. Lu, S.-Z., \& Hellawell, A. (1995). Modification of Al-Si alloys: Microstructure, thermal analysis, and mechanisms. JOM. 47(2): 38-40. 
29. Liao, H., Dong, G., \& Sun, G. (2007). Investigation on influence of sodium- or strontiummodification on corrosion-resistance of Al-11.7\%Si alloy. Journal of Materials Science. 42(13): 5175-5181.

30. Lu, L., Nogita, K., \& Dahle, A. K. (2005). Combining Sr and Na additions in hypoeutectic Al-Si foundry alloys. Materials Science and Engineering: A. 399(1-2): 244-253.

31. Tiedje, N. S., Taylor, J. A., \& Easton, M. A. (2012). Feeding and Distribution of Porosity in Cast Al-Si Alloys as Function of Alloy Composition and Modification. Metallurgical and Materials Transactions A. 43(12): 4846-4858.

32. Shin, S.-S., Kim, E.-S., Yeom, G.-Y., \& Lee, J.-C. (2012). Modification effect of Sr on the microstructures and mechanical properties of Al-10.5Si-2.0Cu recycled alloy for die casting. Materials Science and Engineering: A. 532: 151-157.

33. Dinnis, C. M., Dahle, A. K., Taylor, J. A., \& Otte, M. O. (2004). The influence of strontium on porosity formation in Al-Si alloys. Metallurgical and Materials Transactions A. 35(11): 3531-3541.

34. Srirangam, P., Kramer, M. J., \& Shankar, S. (2011). Effect of strontium on liquid structure of Al-Si hypoeutectic alloys using high-energy X-ray diffraction. Acta Materialia. 59(2): 503-513.

35. Srirangam, P., Chattopadhyay, S., Bhattacharya, A., Nag, S., Kaduk, J., Shankar, S., ... Shibata, T. (2014). Probing the local atomic structure of Sr-modified Al-Si alloys. Acta Materialia. 65: 185-193.

36. Zhang, D. L., \& Cantor, B. (1993). Heterogeneous nucleation of solidification of Si by solid AI in hypoeutectic Al-Si alloy. Metallurgical Transactions A. 24(5): 1195-1204.

37. Fatahalla, N., Hafiz, M., \& Abdulkhalek, M. (1999). Effect of microstructure on the mechanical properties and fracture of commercial hypoeutectic Al-Si alloy modified with $\mathrm{Na}$, Sb and Sr. Journal of Materials Science. 34(14): 3555-3564.

38. Zarif, M., McKay, B., Li, J., \& Schumacher, P. (2010). Study of the Effect of Strontium (Sr) on the Nucleation of Eutectic Silicon (Si) in High Purity Hypoeutectic Al-5Si Alloys. BHM Berg- Und Hüttenmännische Monatshefte. 155(11): 506-511.

39. Zarif, M., Mckay, B., \& Schumacher, P. (2011). Study of Heterogeneous Nucleation of Eutectic Si in High-Purity Al-Si Alloys with Sr Addition. Metallurgical and Materials Transactions A. 42(6): 1684-1691.

40. Liu, L., Samuel, A. M., Samuel, F. H., Doty, H. W., \& Valtierra, S. (2004). Characteristics of $\alpha$-dendritic and eutectic structures in Sr-treated Al-Si casting alloys. Journal of Materials Science. 39(1): 215-224. 
41. Nafisi, S., Ghomashchi, R., \& Vali, H. (2008). Eutectic nucleation in hypoeutectic Al-Si alloys. Materials Characterization. 59(10): 1466-1473.

42. Heiberg, G., \& Arnberg, L. (2001). Investigation of the microstructure of the Al-Si eutectic in binary aluminium-7 wt\% silicon alloys by electron backscatter diffraction (EBSD). Journal of Light Metals. 1(1): 43-49.

43. Sreeja Kumari, S. S., Pillai, R. M., Rajan, T. P. D., \& Pai, B. C. (2007). Effects of individual and combined additions of $\mathrm{Be}, \mathrm{Mn}, \mathrm{Ca}$ and $\mathrm{Sr}$ on the solidification behaviour, structure and mechanical properties of $\mathrm{Al}-7 \mathrm{Si}-0.3 \mathrm{Mg}-0.8 \mathrm{Fe}$ alloy. Materials Science and Engineering: A. 460-461: 561-573.

44. Sreeja Kumari, S. S. S., Pillai, R. M., \& Pai, B. C. (2008). Structure and properties of calcium and strontium treated Al-7Si-0.3Mg alloy: A comparison. Journal of Alloys and Compounds. 460(1-2): 472-477.

45. Heiberg, G., Nogita, K., Dahle, A. K., \& Arnberg, L. (2002). Columnar to equiaxed transition of eutectic in hypoeutectic aluminium-silicon alloys. Acta Materialia. 50(10): 2537-2546.

46. Dinnis, C. M., Dahle, A. K., \& Taylor, J. A. (2005). Three-dimensional analysis of eutectic grains in hypoeutectic Al-Si alloys. Materials Science and Engineering: A. 392(1-2): 440-448.

47. Shabestari, S. G., Keshavarz, M., \& Hejazi, M. M. (2009). Effect of strontium on the kinetics of formation and segregation of intermetallic compounds in A380 aluminum alloy. Journal of Alloys and Compounds. 477(1-2): 892-899.

48. Heusler, L., \& Schneider, W. (2002). Influence of alloying elements on the thermal analysis results of Al-Si cast alloys. Journal of Light Metals. 2(1): 17-26.

49. Kulunk, B., \& Zuliani, D. J. (1996). Applications for the strontium treatment of wrought and die-cast Al. JOM. 48(10): 60-63.

50. McDonald, S. D., Dahle, A. K., Taylor, J. A., \& St. John, D. H. (2004a). Eutectic grains in unmodified and strontium-modified hypoeutectic aluminum-silicon alloys. Metallurgical and Materials Transactions A. 35(6): 1829-1837.

51. Timpel, M., Wanderka, N., Schlesiger, R., Yamamoto, T., Lazarev, N., Isheim, D., ... Banhart, J. (2012). The role of strontium in modifying aluminium-silicon alloys. Acta Materialia. 60(9): 3920-3928.

52. Nogita, K., Yasuda, H., Yoshida, K., Uesugi, K., Takeuchi, A., Suzuki, Y., \& Dahle, A. K. (2006). Determination of strontium segregation in modified hypoeutectic Al-Si alloy by micro X-ray fluorescence analysis. Scripta Materialia. 55(9): 787-790. 
53. Dahle, A. K., Nogita, K., McDonald, S. D., Zindel, J. W., \& Hogan, L. M. (2001). Eutectic nucleation and growth in hypoeutectic Al-Si alloys at different strontium levels. Metallurgical and Materials Transactions A. 32(4): 949-960.

54. Cho, Y. H., Lee, H.-C., Oh, K. H., \& Dahle, A. K. (2008). Effect of Strontium and Phosphorus on Eutectic Al-Si Nucleation and Formation of $\beta$-Al5FeSi in Hypoeutectic Al-Si Foundry Alloys. Metallurgical and Materials Transactions A. 39(10): 2435-2448.

55. McDonald, S. D., Dahle, A. K., Taylor, J. A., \& St. John, D. H. (2004b). Modificationrelated porosity formation in hypoeutectic aluminum-silicon alloys. Metallurgical and Materials Transactions B. 35(6): 1097-1106.

56. McDonald, S. D., Nogita, K., \& Dahle, A. K. (2006). Eutectic grain size and strontium concentration in hypoeutectic aluminium-silicon alloys.Journal of Alloys and Compounds. 422(1-2): 184-191.

57. Liao, H., Sun, Y., \& Sun, G. (2002). Correlation between mechanical properties and amount of dendritic $\alpha$-Al phase in as-cast near-eutectic Al-11.6\% Si alloys modified with strontium. Materials Science and Engineering: A. 335(1-2): 62-66.

58. Haque, M. M., \& Maleque, M. A. (1998). Effect of process variables on structure and properties of aluminium-silicon piston alloy. Journal of Materials Processing Technology. 77(1-3): 122-128.

59. Easton, M., \& StJohn, D. (1999a). Grain refinement of aluminum alloys: Part I. the nucleant and solute paradigms - a review of the literature. Metallurgical and Materials Transactions A, 30(6): 1613-1623.

60. Easton, M., \& StJohn, D. (1999b). Grain refinement of aluminum alloys: Part II. Confirmation of, and a mechanism for, the solute paradigm. Metallurgical and Materials Transactions A, 30(6): 1625-1633.

61. Lu, L., \& Dahle, A. K. (2006). Effects of combined additions of Sr and AlTiB grain refiners in hypoeutectic Al-Si foundry alloys. Materials Science and Engineering: A. 435-436: 288-296.

62. Mallapur, D. G., Kori, S. A., \& Udupa, K. R. (2010). Influence of Ti, B and Sr on the microstructure and mechanical properties of A356 alloy. Journal of Materials Science. 46(6): 1622-1627.

63. Murty, B. S., Kori, S. A., \& Chakraborty, M. (2002). Grain refinement of aluminium and its alloys by heterogeneous nucleation and alloying. International Materials Reviews. 47(1): 3-29. 
64. Lee, Y. C., Dahle, A. K., StJohn, D. H., \& Hutt, J. E. C. (1999). The effect of grain refinement and silicon content on grain formation in hypoeutectic Al-Si alloys. Materials Science and Engineering: A. 259(1): 43-52.

65. Martukanitz, R. P. (1993). Selection and Weldability of Heat-Treatable Aluminum Alloys. ASM Handbook, 6, 528-536.

66. Dickerson, P. B. (1993). Welding of Aluminum Alloys. ASM Handbook, 6, 722-739.

67. Caton, M.J., Jones, J.W., Boileau, J.M., \& Allison, J.E. (1999). The effect of solidification rate on the growth of small fatigue cracks in a cast 319-type aluminum alloy. Metallurgical and Materials Transactions A. 30(12): 3055-3068.

68. Boileau, J.M., \& Allison, J.E. (2003). The effect of solidification time and heat treatment on the fatigue properties of a cast 319 aluminum alloy. Metallurgical and Materials Transactions A. 34(9): 1807-1820.

69. Stone, I. C., \& Jones, H. (1997). Effect of cooling rate and front velocity on solidification micro structure selection in Al-3.5 wt.\% Fe-0 to 8.5 wt.\% Si alloys. Materials Science and Engineering: A. 226: 33-37.

70. Ourfali, M. F., Todd, I., \& Jones, H. (2005). Effect of solidification cooling rate on the morphology and number per unit volume of primary Mg2Si particles in a hypereutectic Al-Mg-Si alloy. Metallurgical and Materials Transactions A. 36(5): 1368-1372.

71. Zhang, J., Fan, Z., Wang, Y. Q., \& Zhou, B. L. (2000). Effect of cooling rate on the microstructure of hypereutectic Al-Mg2Si alloys. Journal of materials science letters. 19(20): 1825-1828.

72. Juarez-Islas, J. A., Warrington, D. H., \& Jones, H. (1989). Formation of stable and metastable phases in Al-Mn alloys by the use of a gravity chill casting technique. Journal of materials science. 24(6): 2076-2080.

73. Hawksworth, A., Rainforth, W. M., \& Jones, H. (1999). Solidification microstructure selection in the Al-rich Al-La, Al-Ce and Al-Nd systems. Journal of Crystal Growth. 197(1): 286-296.

74. Perepezko, J.H., \& Hildal, K. (2006). Analysis of solidification microstructures during wedge-casting. Philosophical Magazine. 86(24): 3681-3701.

75. Norman, A.F., Prangnell, P.B., \& McEwen, R.S. (1998). The Solidification Behaviour of Dilute Aluminum-Scandium Alloys. Acta Materialia. 46(16): 5715-5732.

76. Norman, A.F., Hyde, K., Costello, F., Thompson, S., Birley, S., \& Prangnell, P.B. (2003). Examination of the Effect of Sc on 2000 and 7000 series aluminium castings: For 
improvements in fusion welding. Materials Science \& Engineering: A. 354(1-2): 188198.

77. Rasband, W. S., Image J., U.S. National Institutes of Health, Bethsesda, Maryland, USA, http://imagej.nih.gov/ig/, 1997-2014.

78. Bouchard, D., \& Kirkaldy, J. S. (1997). Prediction of dendrite arm spacings in unsteady- and steady-state heat flow of unidirectionally solidified binary alloys. Metallurgical and Materials Transactions B, 28(4), 651-663.

79. Su, S., Liang, X., Moran, A., \& Lavernia, E. J. (1994). Solidification behavior of an Al-6Si alloy during spray atomization and deposition. International Journal of Rapid Solidification, 8(3), 161-177.

80. Heard, D. W., Brophy, S., \& Brochu, M. (2012). Solid freeform fabrication of Al-Si components via the CSC-MIG process. Canadian Metallurgical Quarterly, 51(3), 302312.

81. ASTM B557-02. Standard Test Methods for Tension Testing Wrought and Cast Aluminumand Magnesium-Alloy Products. ASTM International, West Conshohocken, PA, 2013, www.astm.org.

82. Wang, Q.G. (2003a). Microstructural effects on the tensile and fracture behavior of aluminum casting alloys A356/357. Metallurgical and Materials Transactions A. 34: 2887-2899.

83. Wang, Q. G., \& Davidson, C. J. (2001). Solidification and precipitation behaviour of Al-SiMg casting alloys. Journal of materials science, 36 (3): 739-750.

84. Kou, S. (1987). Welding Metallurgy. New York: John Wiley \& Sons.

85. Tiryakioglu, M., \& Staley, J.T. (2003). Physical Metallurgy and the Effect of Alloying Additions in Aluminum Alloys. In G.E. Totten \& D.S. MacKenzie (Eds.), Handbook of Aluminum Volume 1 (81-209). New York: Marcel Dekker, Inc.

86. Wang, Q.G., Caceres, C.H., \& Griffiths, J.R. (2003b). Damage by eutectic particle cracking in aluminum casting alloys A356/357. Metallurgical and Materials Transactions A. 34: 2901-2912.

87. Drouzy, M., Jacob, S., \& Richard, M. (1980). Interpretation of tensile results by means of quality index and probable yield strength - application to Al-Si Mg foundry alloys France. International Cast Metals Journal, 5(2): 43-50.

88. Tiryakioglu, M., \& Campbell, J. (2014). Quality Index for Aluminum Alloy Castings. International Journal of Metalcasting, 8(3): 39-42. 